УДК: 634.987:581.192

\title{
СОДЕРЖАНИЕ КАТЕХИНОВ В ПЛОДАХ НЕКОТОРЫХ ДИКОРАСТУЩИХ ПЛОДОВО-ЯГОДНЫХ РАСТЕНИЙ, ПРОИЗРАСТАЮЩИХ В АЗЕРБАЙДЖАНЕ
}

\author{
(C) Л.A. Мустафаева \\ Институт ботаники НАН Азербайджана, Патамдартское шоссе, 40, Баку, \\ 3700073 (Азербайджан), e-mail: latafat_shamsizade@mail.ru
}

Исследовано содержание катехинов в плодах 36 видов растений из 18 родов 6 семейств, произрастающих в Азербайджане. В результате установлено, что количество катехинов в плодах колеблется в интервале 27,8-502,2 мг\%. Растения с высоким содержанием катехинов сосредоточены в родах Crataegus L., Sorbus L., Viburnum L., Berberis L., Rosa L., Cornus L., Hippophae L. При накоплении катехинов в плодах, в зависимости от места произрастания и географических факторов, обнаружены межродовые и внутривидовые различия. С повышением высоты местности над уровнем моря увеличивается содержание катехинов. Высокое содержание катехинов характерно для плодов дикорастущих плодово-ягодных растений Азербайджана.

Ключевые слова: катехины, дикорастущие, плоды, Азербайджан

\section{Введение}

Катехины относятся к основному типу полифенольных соединений растительного происхождения, содержатся в большинстве съедобных плодах и ягодах, в побегах чайного растения, бобах какао и др. В растительном материале они могут существовать в форме гликозидов.

По количественному содержанию катехины в растениях занимают одно из ведущих мест. Они широко распространены и обнаружены во всех частях плодово-ягодных растений. Столь широкое распространение катехинов убедительно говорит об их существенном значении в жизни растений.

В литературе имеются обширные сведения, показывающие большую роль катехинов в жизни растений, участие их в обмене веществ. Они являются биологически активными веществами растительного происхождения.

Исследованием химического состава плодово-ягодных растений занимались многие исследователи [1-9]. О содержании катехинов в дикорастущих плодово-ягодных растениях имеются очень мало сведений [10-11]. Продолжая изучение биохимического состава, мы исследовали катехинов в некоторых дикорастущих плодово-ягодных растениях, произрастающих в Азербайджане.

\section{Экспериментальная часть}

Объектом исследования были следующие плодово-ягодные растения, произрастающие в Азербайджане: Ribes orientale Desf., R. biebersteinii Berl. ex DC. (p. Ribes L.) сем. Crossulariaceae DC; Berberis orientalis Schneid., B.vulgaris L., B.densiflora Boiss. et Buhse (p.Berberis L.) ceм. Berberidaceae Juss.; Viburnum opulus L., V.lantana L., (p. Viburnum L.) сем. Viburnaceae Rafin., Cornus mas L. (p. Cornus L.) сем. Cornaceae Dumort.; Elaeagnus angustifolia L., (p. Elaeagnus L.), Hippophae rhamnoides L. (p. Hippophae L.) сем. Elaeagnaceae Juss.; Mespilus germanica L., (p. Mespilus L.) Malus orientalis Uglitzk (p. Malus Hill), Cydonia oblonga Mill, (p. Cydonia Hill.), Sorbus torminalis (L.) Crantz., S. qraeca (Spach) Lodd. ex Schauer, S.

Мустафаева Лятафат Ахад кызы - ведущий научный сотрудник, кандидат биологических наук, доцент, e-mail: latafat_shamsizade@mail.ru caucasica Zinserl, S. caucasigena Kom. ex Gatsch., (p. Sorbus L.); Crataegus pentagyna Waldst. et Kit., C. kyrtostyla auct. $=C$ curviesepala Lindm., $C$. orientalis 
Pall. ex Bieb., C. caucasica C. Koch. (p. Crataegus L.), Cerasus incana (Pall.) Spach., C. microcarpa (C.A.Mey.) Boiss. (p. Cerasus Hill.), Pyrus caucasica Fed (p.Pyrus L.), Fragaria vesca L. (p. Fragaria L.), Amelanchier. Rotundifolia (Lam.) Dum. - Cours.=A. ovalis (p. Amelanchier Medik.), Prunus divaricata Ledeb., P. spinosa, L., P. caspica Koval. et Ekim. (p. Prunus), Rosa canina L., R. corymbifera Borkh., R. micrantha Smith., R. spinosissima L. (p. Rosa L.), Pyracantha coccinea. M. Roem (p. Pyracantha M. Roem.), Cotoneaster integerrimus Medik., C. melanocarpa M. Pop. (p. Cotoneaster Medik.) из семейства Rosaceae Juss.

Анализы были проведены в течение 2009-2011 гг. Плоды для анализа были собраны из 10 особей со всех сторон кроны в период биологической зрелости, из разных районов Азербайджана, фиксированы спиртом и до проведения анализов хранились в холодильнике.

Среднюю пробу плодов приготовили по общепринятой методике [12]. Средняя проба составляла не менее 1 кг. Содержание катехинов определяли по методу, предложенному В.Л. Вигоровым [10]; расчет количества катехинов проводили по калибровочной кривой, для построения которой использовали суммарный препарат катехинов чая.

\section{Обсуждение результатов}

Результаты проведенных исследований дикорастущих плодово-ягодных растений показали, что они богаты катехинами (таб. 1). Из данных таблицы видно, что количество катехинов в плодах изученных видов колеблется в широких пределах 27,8-502,2 мг\%. Эти колебания существенны не только в пределах всей группы изучаемых растений, но и в пределах каждого рода, а зачастую и вида. Из данных таблицы видно, что плоды исследованных видов содержат достаточное количество катехинов.

Изученные плоды видов калины отличаются высоким содержанием катехинов (228,2-331,4 мг\%). Плоды Viburnum lantana L., собранные из двух разных пунктов, отличались по количественному содержанию катехинов. Плоды, произрастающие в лесу, вблизи села Авран, Гусарского района содержат 228,2 мг\%, а плоды того же вида, но произрастающие в лесу вблизи села Халхал Огузского района, содержат 254,3 мг\%. Плоды вида калины Viburnum opulus, произрастающие в лесах около села Гыпчак Гахского района, содержит 331,4 мг\% катехинов.

Bce плоды видов рода Ribes L. отличаются высоким содержанием катехинов. Наибольшее количество катехинов имеют плоды Ribes biebersteinii (328 мг\%), более низкое количество имеют плоды $R$. orientale $(176,3 \mathrm{мг} \%)$.

Высокое количество катехинов обнаружено в плодах видов семейства Berberidaceae Juss. Виды барбариса, имеющие наиболее высокое количество катехинов в плодах значительно разнятся по этому показателю. Berberis vulgaris имеет катехинов 189,4-229,1 мг\%, а плоды B. densiflora почти вдвое меньше 134,3-158,2 мг\%. Плоды вида B. orientalis, произрастающие в Губинском районе, содержат 176,2 мг\%, а плоды того же вида, но произрастающие в лесах Шекинского района, содержат 205,6 мг\% катехина. Данные показывают, что содержание катехинов в плодах видов рода Berberis L. зависит от многих факторов, в частности, от условий внешней среды и видовых особенностей (табл. 1).

Таблица 1. Содержание катехинов в плодах некоторых плодово-ягодных растений (мг \% на сырой вес)

\begin{tabular}{|c|c|c|c|}
\hline \multirow{2}{*}{ Семейство, род, вид } & \multirow{2}{*}{ Место произрастания } & \multicolumn{2}{|c|}{ Количество } \\
\hline & & катехинов & образцов \\
\hline 1 & 2 & 3 & 4 \\
\hline \multicolumn{4}{|c|}{ Ceм. Grossulariaceae DC. } \\
\hline p. Ribes L. & & & \\
\hline$R$. orientale Desf. & Губинский район, в лесу вблизи села Гайтан & 176,3 & 4 \\
\hline R.biebersteinii Berl. ex DC. & Огузский район, на усадьбе, около села Халхал & 328,3 & 9 \\
\hline \multicolumn{4}{|c|}{ Сем. Berberidaceae Juss. } \\
\hline p. Berberis $\mathbf{L}$. & & & \\
\hline B. orientalis Schneid. & Губинский район, на окраине леса вблизи села Гайтан & 176,2 & 5 \\
\hline B.orientalis Schneid. & $\begin{array}{l}\text { Шекинский район в лесу, среди кустарников, около села } \\
\text { Зайзит }\end{array}$ & 205,6 & 8 \\
\hline B. vulgaris $\mathrm{L}$. & Исмаиллинский район, на усадьбе среди кустарников & 229,1 & 7 \\
\hline B. vulgaris $\mathrm{L}$. & Исмаиллинский район, в лесу, около села Чайговушан & 189,4 & 6 \\
\hline
\end{tabular}


Продолжение таблищы 1

\begin{tabular}{c|l|c|c}
\hline \multicolumn{1}{c|}{} & \multicolumn{1}{|c|}{2} & \multicolumn{1}{|c}{3} & 4 \\
\hline B.densiflora Boiss. et Buhse. & $\begin{array}{l}\text { Девечинский район, в кустарниковом лесу, вблизи села } \\
\text { Мешриф }\end{array}$ & 134,3 & 5 \\
B. densiflora Boiss. et Buhse. & Исмаиллинский район, в лесу, около села Чайговушан & 158.2 & 6 \\
\hline
\end{tabular}

\begin{tabular}{l|l|r|r}
\hline \multicolumn{1}{c|}{ p. Viburnum L. } & \multicolumn{2}{c}{ Сем. Viburnaceae Rafin. } & \\
V.opulus L. & Гахский район, в лесу, около села Гыпчак & 331,4 & 3 \\
V.lantana L. & Гусарский район, в лесу около села Авран & 228,2 & 5 \\
V.lantana L. & Огузский район, в усадьбе, вблизи села Халхал & 254,3 & 6 \\
\hline
\end{tabular}

\begin{tabular}{l|l|c|c}
\hline \multicolumn{1}{c|}{ p. Cornus L. } & \multicolumn{1}{c}{ Сем. Cornaceae Dumort. } & \\
C. mas L. & $\begin{array}{l}\text { Гусарский район, в лесу, среди кустарникового леса, } \\
\text { вблизи села Кузун }\end{array}$ & 124,6 \\
\hline
\end{tabular}

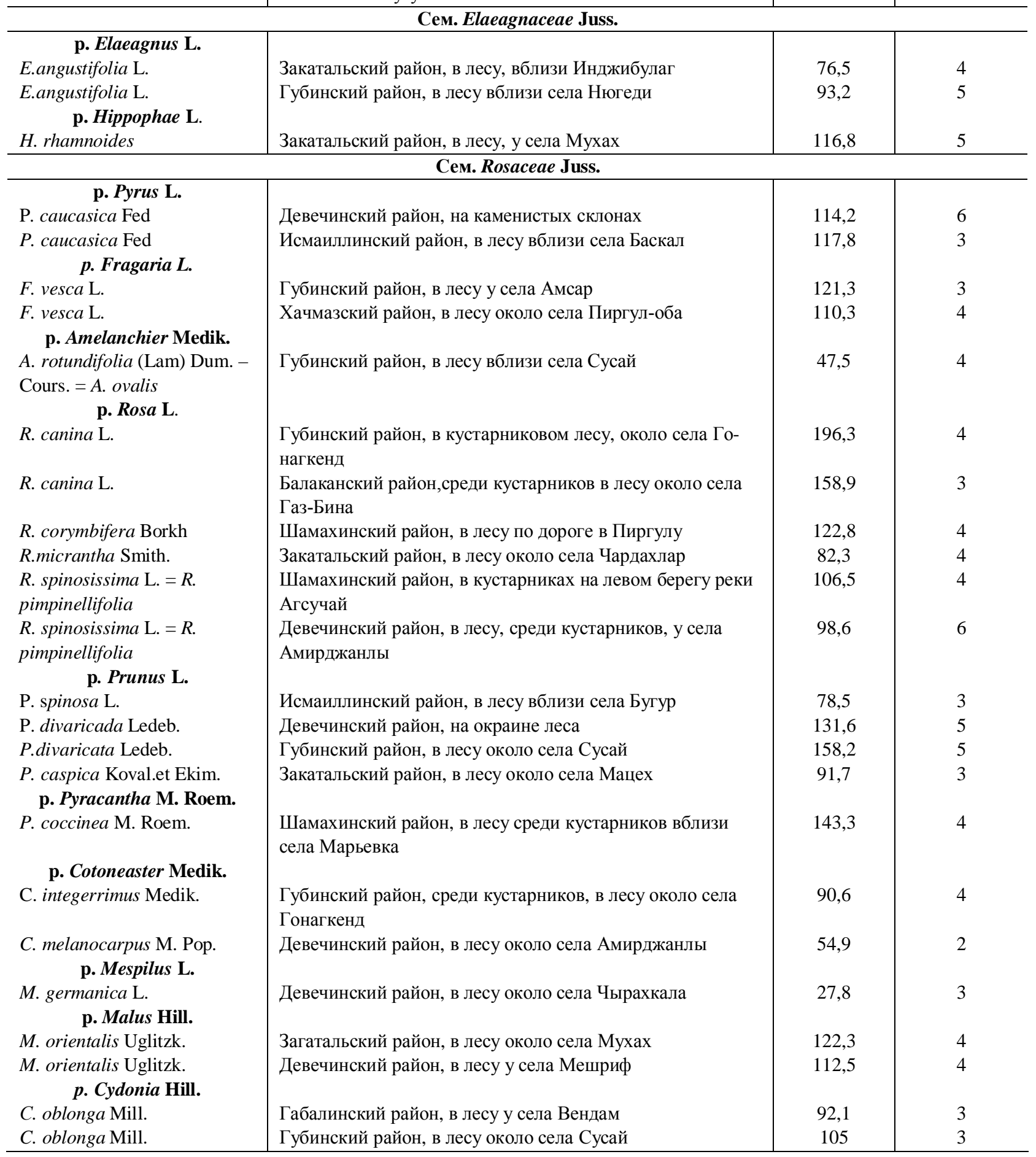


Окончание таблищы 1

\begin{tabular}{l|l|c|c}
\hline \multicolumn{1}{c|}{ p. Sorbus L. } & \multicolumn{1}{c|}{2} & 3 & 4 \\
\hline \multicolumn{1}{c|}{} & & & \\
S.caucasica Jinserl. & Губинский район, в лесу вблизи села Хаитал & 276,2 & 4 \\
S.caucasica Jinserl. & Девечинский район, в лесу около села Чыракгала & 258,4 & 4 \\
S. torminalis (L) Grantz. & Исмаиллинский район, в лесу около села Топчу & 388,31 & 6 \\
S.caucasigena Kom.ex & Губинский р-н, на опушке леса у села Сусай & 157,3 & 7 \\
Catsch. = S. aucuparia & Там же & 78,9 & 8 \\
S.graeca (Spach) Lodd. ex & & & \\
Shauer. & & & \\
\hline
\end{tabular}

\begin{tabular}{|c|c|c|c|}
\hline \multicolumn{4}{|c|}{ p.Crataegus L. } \\
\hline C. pentagyna Waldst et Kit. & Худатский район, на окраине леса, возле моря & 502,2 & 7 \\
\hline C. pentagyna Waldst et Kit. & Огузский район, в лесу вблизи села Халхал & 135,6 & 7 \\
\hline $\begin{array}{l}\text { C. kyrtostyla auct. }=C . \\
\text { curvisepala } \text { (Lindm.) }\end{array}$ & Губинский район, в лесу около села Яллы & 170,4 & 7 \\
\hline $\begin{array}{l}\text { C. kyrtostyla auct. }=C . \\
\text { curvisepala } \text { (Lindm.) }\end{array}$ & Хачмазский район, в лесу у села Измайловка & 196,7 & 4 \\
\hline C.orientalis Pall. ex Bieb. & $\begin{array}{l}\text { Шамахинский район, в лесу среди кустарников у села } \\
\text { Шорбалы }\end{array}$ & 457,2 & 4 \\
\hline C.caucasica C.Koch. & Губинский район, в лесу вблизи села Кубанчы & 147,2 & 5 \\
\hline \multicolumn{4}{|c|}{ p. Cerasus Hill. (Microcerasus (Spach.) M. Roem.) } \\
\hline C. incana (Pall) Spach & Шекинский район, в лесу у села Зайзит & 50,1 & 3 \\
\hline C.incana (Pall) Spach & Шекинский район, в лесу у села Башлайск & 43,6 & 3 \\
\hline $\begin{array}{l}\text { C. microcarpa (C.A.Mey.) } \\
\text { Boiss. }\end{array}$ & Габалинский район, в лесу у села Вендам & 54,7 & 4 \\
\hline $\begin{array}{l}\text { C. microcarpa (C.A.Mey.) } \\
\text { Boiss. }\end{array}$ & Огузский район, в лесу вблизи села Халхал & 48,2 & 4 \\
\hline
\end{tabular}

По содержанию катехинов наибольшая изменчивость отмечена в плодах видов семейства Elaeagnaceae Juss. Виды рода Elaeagnus L. отличаются небольшим содержанием катехинов (76,5-93,2 мг \%).

По сравнению с видами рода Elaeagnus L., род Hippophae L. из семейства Elaeagnaceae содержит более высокое количество катехинов (116,8 мг\%).

Результаты анализов плодов (Hippophae rhamnoides L.) облепихи свидетельствуют о большой вариабельности по содержанию катехинов. Содержание катехинов в плодах облепихи по сравнению со многими плодово-ягодными растениями достаточно высокое, в пределах 78,5-116,8 мг \%. Наиболее высоким содержанием катехинов отличаются плоды, произрастающие в окрестности села Мухах Загатальского района. Видимо, это связано не только с биологической особенностью видов облепихи, приобретенной в период эволюции, а также от места ее произрастания.

Катехины в плодах Cornus mas L. составляют основную часть полифенолов. В плодах кизила содержание катехинов колеблется в пределах 110,2-124,6 мг\%.

В исследованных видах семейства Rosaceae Juss катехины в плодах варьируют довольно в больших интервалах (27,8-502,2 мг\%). Высоким содержанием катехинов отличаются виды рода Sorbus L., Crataegus L., Rosa L., Pyrus L., Fragaria L., Prunus L., a самым наименьшим - плоды Mespilus L.

Общее количество катехинов плодов видов Malus orientalis варьирует в пределах 112,5-122,3 мг \% . Наибольшее количество катехинов отмечено в плодах Cydonia oblonga, произрастающих в лесах Сусай Губинского района (105 мг\%), чем в плодах, произрастающие в лесах Габалинского района $(92,1$ мг\%).

Общее количество катехинов плодов видов рода Pyrus L. колеблется в пределах 114,2-117,8 мг\%. Плоды вида Р. caucasica, собранные в лесах Исмаиллинского района, содержат катехинов больше $(117,8$ мг\%), чем плоды того же вида, но произрастающие в лесах Девечинского района (114,2 мг\%).

Из исследуемых видов наименьшее количество катехинов было обнаружено в плодах Mespilus germanica, Cotoneaster melanocarpa, Amelanchier rotindifolia (27,8 мг\%; 54,9 мг\%; 47,5 мг\% соответственно).

Высокое количество катехинов отмечено в плодах видов рода Rosa L. Общее количество катехинов в плодах колеблется в пределах 98,6-196,3 мг\%. Из исследованных 4 видов наибольшее количество катехинов отмечено у видов Rosa canina, R. corymbifera (196,3; 122,8 мг\% соответственно), а наименьшее - в плодах вида $R$. micrantha $(82,3$ мг\%). 
Среди исследованных видов семейства Rosaceae Juss., наибольшее количество катехинов содержится в плодах видов рода Crataegus L. (147,2-502,2 мг\%). В плодах C. pentagyna и $C$. kyrtostyla = C. curviesepala накапливается 502,4-196,7 мг\% катехинов соответственно. Несколько уступают им виды C. orientalis и C. caucasica. По содержанию катехинов плоды видов рода Crataegus L., различаются также между собой. Плоды вида Crataegus pentagyna, произрастающие возле моря, на окраине леса Худатского района, содержат 502,2 мг\%, а плоды того же вида, но произрастающие в другом районе, в лесу, вблизи села Халхал, Огузского района содержат 135,6 мг\% катехина. Резюмируя вышесказанное, можно отметить, что общее количество катехинов в плодах зависит от места их произрастания.

По содержанию катехинов, плоды исследованных видов рода Sorbus L. превосходят плоды видов рода Rosa L., Berberis L., Ribes L., не уступают плодам Sorbus aucuparia L., произрастающей в Белоруссии и в Московской обл. [3, 5] и могут быть использованы в качестве источника катехинов.

Общее количество катехинов плодов видов Sorbus колебляется в пределах 78,9-388,3 мг\%. Из исследуемых видов только плоды $S$. graeca имеют сравнительно низкое количество катехинов (78,9 мг\%), а самое наибольшее количество катехинов накапливаются в плодах S. torminalis $(388,3$ мг\%) Плоды $S$. caucasigena имеют довольно большое количество катехинов (157,3 мг\%). Если проследить за изменением содержания катехинов плодов рябины кавказской в связи с местами произрастания, приходим к заключению, что вертикальная зональность, в частности, повышение высоты местности над уровнем моря, сопровождается увеличением общего количества катехинов.

Общее накопление катехинов в исследованных видах рода Prunus L. составляет 78,5-158,2 мг\%. Наибольшее количество катехинов сосредоточено в плодах P. divaricata (131,6-158,2 мг\%), наименьшее в P. spinosa (78,5 мг\%). Колебания общего количества катехинов вида (формы алычи с плодами различной окраски) и даже между видами не столь ощутимы, как в пределах вида произрастающие в разных экологических условиях. Здесь особую роль играет географический фактор. Растения, произрастающие на низменности, содержат меньшее количество катехинов, чем растения, произрастающие в предгорных и среднегорных поясах.

Общее количество катехинов плодов вида Fragaria vesca довольно высокое и колеблется в пределах 110,3-121,3 мг\%. Приходим к такому заключению, что вертикальная зональность, в частности, повышение высоты местности над уровнем моря, сопровождается увеличением общего количества катехинов.

Небольшое количество катехинов накапливаются в плодах видов рода Cotoneaster Medik., Pyracantha M. Roem. (90,6; 143,3 мг\% соответственно).

Привлекательность, высокие вкусовые качества плодов видов рода Cerasus. уверенно определяют конкурентоспособность его видов. Плоды имеют разнообразный и достаточно богатый биохимический состав, который определяет их ценность и необходимость использования в питании как в качестве источника пополнения комплекса витаминов в организме человека, так и для лечебных целей [2, 4]. Согласно литературным данным, плоды видов рода Cerasus Hill. являются ценным источником витаминов: C (аскорбиновая кислота), Р (цитрин), Е (токоферол), В 1 (тиамин), В 2 (рибофлавин), РР (ниацин) и В-каротин (провитамин А-ретинол). В плодах Р-активные вещества представлены также и комплексом катехинов. Результаты проведенных исследований в плодах видов рода Cerasus Hill. позволили выявить значительные видовые различия по содержанию основных биохимических соединений, в том числе и катехинов.

Представленные многолетние данные по содержанию катехинов в плодах видов рода Cerasus Hill., показывают, что они по сравнению с другими изученными плодово-ягодными растениями содержат небольшое количество катехинов (48,2-54,7 мг\%).

Помимо суммарного количества катехинов, впервые было исследовано также и распределение их в различных органах некоторых плодово-ягодных растений (табл. 2).

Таблица 2. Распределение катехинов по органам растений (мг \%)

\begin{tabular}{c|c|c}
\hline \multirow{2}{*}{ Органы растений } & \multicolumn{2}{|c}{ Виды } \\
\cline { 2 - 3 } & Ribes Biebersteini & Cerasus incana \\
\hline Корень & 1218,4 & 81,6 \\
Стебель & 815,1 & 53,4 \\
Лист & 443,8 & 47,5 \\
Плоды & 328,3 & \\
\hline
\end{tabular}


Таким образом, установлено, что катехины неравномерно распределяются по органам растений. Независимо от видовых особенностей растений, наибольшее количество катехинов накапливаются в корнях, а наименьшее - в плодах. В корнях содержание катехинов в исследуемых растениях варьируются в пределах 117,3-1218 мг\%; в стеблях - 81,6-1011,0 мг\%; в листьях - 53,4-989,0 мг\%; в плодах - 47,5-902,2 мг\%. Наибольшее накопление катехинов во всех частях растений установлено у вида Ribes Biebersteinii (1218,4; 815,$1 ; 443,8 ; 328,3$ мг\% в корнях, стеблях, листьях, плодах соответственно), а наименьшее - у вида Cerasus incana $(117,3 ; 81,6 ; 53,4 ; 47,5$ мг\% соответственно).

\section{Выводы}

По количественному содержанию катехинов в плодах дикорастущих растений существуют немалые межродовые и даже внутривидовые различия, зависящие, как правило, от особенностей вида и условии внешней среды. Однако свойство накапливать то или иное количество катехинов в плодах растения сохраняют достаточно устойчиво в течение всей жизни. Плоды всех дикорастущих плодовых отличаются высоким количеством катехинов.

Наибольшее количество катехинов содержатся в плодах видов Crataegus pentagyna (502,2 мг\%), C. orientalis (457,3 мг\%), Sorbus torminalis (388,31 мг\%), Viburnum opulus (331,4 мг\%), Ribes biebersteinii (328,3 мг\%).

Для изучении катехинов некоторых дикорастущих плодово-ягодных растений были использованы различные органы растения. Проведенные анализы показали, что катехины неравномерно распределены по органам растений. Наибольшее накопление катехинов было обнаружено в корнях, а наименьшее - в плодах.

Количественное содержание катехинов исследованных видов показывает, что все их органы вполне могут быть сырьем для получения Р-витаминоактивных препаратов.

\section{Список литературь}

1. Борух И.Ф. Биологически активные вещества некоторых дикорастущих плодов // Труды семинара по биологически активным веществам плодов и ягод. М., 1976. С. 174-176.

2. Горбунов А.Б., Васильева В.Н., Смагин В.С. Дикорастущие и культивируемые в Сибири ягодные и плодовые растения. Новосибирск, 1980. 284 с.

3. Метлицкий Л.В. Основы биохимии плодов и овощей. М., 1978., 307 с.

4. Новрузов Э.Н. Пигменты репродуктивных органов растений и их значение. Баку, 2010. 308 с.

5. Новрузов Э.Н., Шамсизаде Л.А. Биохимическая характеристика плодов видов Rosaceae Juss., произрастающих на Большом Кавказе (в пределах Азербайджана) // Известия НАН Азербайджана. Сер. биол. наук. 2004. №1-2. С. 72-83.

6. Новрузов Э.Н., Шамсизаде Л.А. Химический состав плодов некоторых видов Rubus L., флоры Азербайджана // Растительные ресурсы. 1985. Т. 21, вып. 3. С. 340-343.

7. Новрузов Э.Н. Химический состав плодов дикорастущих плодово-ягодных растений Азербайджана // Растительные ресурсы. 1988. Т. 24, вып. 1. С. 48-51.

8. Ц Церевитинов Ф.В. Химия и товароведение свежих плодов и овощей. М., 1949. Т. 1. 611 с.; Т. 2,511 с.

9. Шапиро Д.К., Михайловская В.А., Манцеводо И.И. Дикорастущие плоды и ягоды. Минск, 1983. 153 с.

10. Вигоров Л.И. Определение различных форм катехинов в плодах и ягодах // Труды II Всесоюзного семинара по биологически активным (лечебным) веществам плодов и ягод. Свердловск, 1964. С. 310-322.

11. Беланова Н.А., Карпов С.И., Чепелева Е.О., Селеменев В.Ф. Определение (+) катехина в тонком слое сорбента актуальные проблемы теории адсорбции, пористости и адсорбционной селективности // Материалы XIV Всероссийского симпозиума с участием иностранных ученых. М., 2010. С. 228.

12. Ермаков А.И. Методы биохимического исследования растений. Л., 1972. 456 с.

Поступило в редакиию 5 октября 2012 г.

После переработки 26 ноября 2012 г. 
Mustafaeva L.A. THE CONTENTS CATECHINS IN FRUITS OF SOME WILD-GROWING FRUIT AND BERRY PLANTS GROWING IN AZERBAIJAN

Institute of Botany of the National Academy of Sciences of Azerbaijan, Patamdartskoe shosse, 40, Baku, 3700073 (Azerbaijan),e-mail: latafat_shamsizade@mail.ru

The contents of catechins in fruits of 36 species of plants from 18 genera of 6 families growing in Azerbaijan is investigated. As a result established that the quantity catechins in fruits fluctuates in the range of $27,8-502,2 \%$. Plants with the high contents catechins are concentrated in species Crataegus L., Sorbus L., Viburnum L., Berberis L., Rosa L., Cornus L., Hippophae L. Found intergeneric and intraspecific diferences in accumulation of these substances depending on a place of growth and geographical factors. With increase of height of the district the contents catechins above sea level increases. The characteristic sign of fruits of wild-growing fruit and berry plants of Azerbaijan is the high contents of catechins.

Keywords: catechins, wild-growing, fruits, Azerbaijan

\section{References}

1. Borukh I.F. Trudy seminara po biologicheski aktivnym veshchestvam plodov i iagod. [Proceedings of the Seminar on the biologically active substances of fruits and berries.]. Moscow, 1976, pp. 174-176. (in Russ.).

2. Gorbunov A.B., Vasil'eva V.N., Smagin V.S. Dikorastushchie i kul'tiviruemye v Sibiri iagodnye i plodovye rasteniia. [Wild and cultivated in Siberia berry and fruit plants.]. Novosibirsk, 1980, 284 p. (in Russ.).

3. Metlitskii L.V. Osnovy biokhimii plodov i ovoshchei. [Fundamentals of Biochemistry of fruits and vegetables.]. Moscow, 1978, 307 p. (in Russ.).

4. Novruzov E.N. Pigmenty reproduktivnykh organov rastenii $i$ ikh znachenie. [Pigments of the reproductive organs of plants and their value.]. Baku, 2010, 308 p. (in Russ.).

5. Novruzov E.N., Shamsizade L.A. Izvestiia NAN Azerbaidzhana. Ser. biol. Nauk, 2004, no. 1-2, pp. 72-83. (in Russ.).

6. Novruzov E.N., Shamsizade L.A. Rastitel'nye resursy, 1985, vol. 21, no. 3, pp. 340-343. (in Russ.).

7. Novruzov E.N. Rastitel'nye resursy, 1988, vol. 24, no. 1, pp. 48-51. (in Russ.).

8. Tserevitinov F.V. Khimiia $i$ tovarovedenie svezhikh plodov $i$ ovoshchei. [Commodity Chemicals and fresh fruit and vegetables.]. Moscow, 1949, vol. 1. 611 p.; vol. 2, 511 p. (in Russ.).

9. Shapiro D.K., Mikhailovskaia V.A., Mantsevodo I.I. Dikorastushchie plody i iagody. [Wild fruits and berries.]. Minsk, 1983, 153 p. (in Russ.).

10. Vigorov L.I. Trudy II Vsesoiuznogo seminara po biologicheski aktivnym (lechebnym) veshchestvam plodov i iagod. [Proceedings of the II All-Union Seminar on the biologically active (therapeutic) substances of fruits and berries.]. Sverdlovsk, 1964, pp. 310-322. (in Russ.).

11. Belanova N.A, Karpov S.I., Chepeleva E.O, Selemenev V.F. Materialy XIV Vserossiiskogo simpoziuma s uchastiem inostrannykh uchenykh. [Proceedings of the XIV All-Russian symposium with international participation.]. Moscow, 2010, pp. 228. (in Russ.).

12. Ermakov A.I. Metody biokhimicheskogo issledovaniia rastenii. [Methods for biochemical study of plants.]. Leningrad, 1972, 456 p. (in Russ.).

Received October 5, 2012

Revised November 26, 2012 
